Suzana Polić-Radovanović

YUBIN

Anđelka Milosavljević

Mašinski fakultet Beograd

Miomir Korać

Arheološki institut Beograd

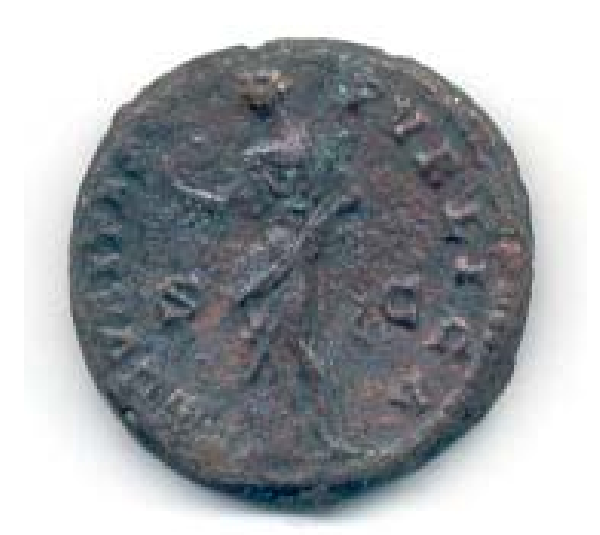

UDK 902.6:621.375.826

\title{
IDENTIFIKACIJA ARHEOLOŠKIH MATERIJALA LASEROM POMOĆU KOMPARATIVNE ANALIZE EKVIVALENTNIH OSNOVA
}

\begin{abstract}
ABSTRAKT
U oblasti konzervacije i restauracije, primena nauke o materijalima ima fundamentalan značaj za objekat ili kolekciju koji su predmet zaštite. Nove tehnologije, a prevashodno savremene laserske tehnike omogućavaju dijagnosticiranje stanja, daju odgovore o optimalnim uslovima čuvanja i mogućnostima preventivne zaštite i kontrole eksponata.

U ovom radu prikazani su rezultati primene lasera na materijalima ekvivalentne osnove sa materijalima novčića kovanih u Viminaciijumu, glavnom gradu rimske provincije Gornje Mezije.

KLJUČNe REČI: NOVE TEHNOLOGIJE, LASERI, ARHEOLOŠKI PREDMETI, MATERIJALI, STRUKTURNE PROMENE
\end{abstract}

Metode i tehnike u konzervaciji i restauraciji kulturnih dobara zasnivaju se na analizi iskustava prošlosti i znanja sa jedne strane i na kreativnom i intuitivnom sagledavanju mogućih rešenja sa druge strane. Uloga eksperata u oblasti nauke o materijalima primenjene na zaštitu kulturnih dobara, zahteva poznavanje široke palete materijala i njihovih svojstava, kao i inovativan pristup i osećaj za suptilnost primenjenih metoda zaštite.

Osnova za harmonično sadejstvo tehnologije i kulture je usaglašeni specifični jezik konzervacije, ${ }^{1}$ koji obuhvata probleme strukture materijala, kvaliteta opreme, energije, istraživanja, investicija, okruženja, timskog rada, organizacije i upravljanja.

1. Milosavljević, Polić-Radovanović, Radovanović, 2002.
Svaka analiza mogućeg delovanja lasera na predmete kulturne baštine, polazi od poznavanja ekvivalentnih osnova materijala u skladu sa konceptom nedestruktivnog, i kada je to moguće, beskontaktnog delovanja.

Od vremena eneolita, do bronzanog doba, arheološka istraživanja pokazala su da je umeće korišćenja bakra obeležilo prirodne etape čovekovog razvoja. Datiranost predmeta sa nalazišta u Ali Košu i Tepešiju² odnosi se na period od osam hiljada godina pre n.e., a napredak u savladavanju ovog materijala može se pratiti dinamikom uvođenja različitih legura na bazi bakra, od kojih je bronza svakako najčešće primenjivana.

2. Vejming Li, 2006. 


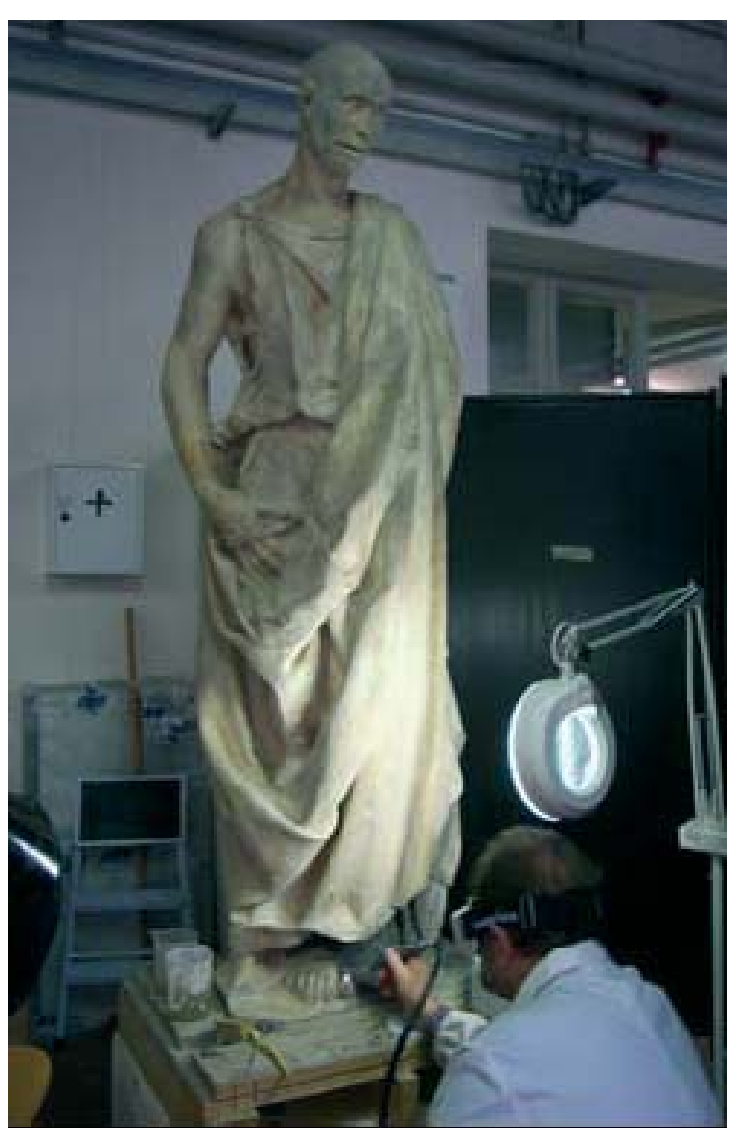

Slika 2 Laser u restauraciji skulptura

Defekti i primese u materijalima, koji narušavaju arheološke predmete (dislokacije, mikro-defekti, intersticijski uključci, supstitucione i intersticijalne primese), direkno utiču na vek artefakta. ${ }^{1}$ Postoje i uticaji koji se odnose na početni kvalitet materijala, nedovoljno poznavanje materijala i postupaka obrade, nepodesnost i nepreciznost alata, upotrebu materijala koji ne odgovaraju nameni u nedostatku potrebnog materijala.

Za prepoznavanje suštine problema restauracije arheoloških predmeta koji sadrže navedene nedostatke, neophodno je imati informacije o obliku, karakteristikama i dimenzijama narušavanja. ${ }^{2}$

U praksi se takve informacije dobijaju iz analize optičkih, mehaničkih, termičkih i drugih parametara, koji mogu dati osnovu za korišćenje poznatih algoritama potrebnih mera dejstva na materijale kulturne baštine, uz njihovo bitno usavršavanje.
1. Pini R. et al., 2000.
2. Milosavljević A. et al., 1996.

Fenomenološki su interesantni prodori u nevidljive strukture bilo da se oni odvijaju na mikro ili makro nivou, i bez obzira da li nam daju okvirni ili detaljni pregled života materije, ukoliko nastanak i proces degradacije posmatramo kao proces kretanja. Ta kretanja imaju različite tragove prošlog, a njihovo razumevanje znači mogućnost ulaska u različite kulture, dok njihovo tumačenje upućuje i na mogućnost vrednovanja. Pokazuje se da čovekovo delovanje sadrži uvek jedan veoma značajan momenat tumačenja onog što se kao fiksirana smisaona struktura izuzima iz vremena, da bi svojom rezistentnošću prema prolaznosti, upravo svedočilo o vremenu.

$\mathrm{U}$ tom smislu analiza ekvivalentnih osnova materijala postaje komparativna prednost novih tehnologija u odnosu na klasične metode u restauraciji i konzervaciji arheoloških predmeta.

Laser kao sredstvo koje katalizuje i realizuje istraživanja ontonomije materijala kulturne baštine, u egzistencijalnom ogledalu polivalentnih procesa rušenja receptivnih barijera naučnotehnološko-umetničkog interegnuma, zahteva multidisciplinarni pristup u oblasti zaštite predmeta kulturne baštine. Specifičan prilaz laserskoj obradi, obzirom da se na istoj stanici, izborom optičkih parametara, dužinom dejstva, energije ili ponavljanja operacije, postižu različite operacije (razdvajanja ili spajanja, ojačavanja ili odgrevanja), zahteva kompleksan metodološki pristup ${ }^{3}$ modeliranju na bazi termalnih, gasodinamičkih modela i modela sličnosti, sve do stanja dezintegracije.

Modeli interakcije se razvijaju u vezi sa određenom tehnološkom operacijom, ali i za dijapazone energije, snage i gustine fluksa u kojima se kreće skala prouzrokovanih fizičkih fenomena, (od faznih i strukturnih transformacija do razrušenja nepoželjnih slojeva).

Primena lasera u zaštiti kulturne baštine posebno je zanimljiva u odnosu na fenomen plastičkog, ${ }_{4}$ jer se klasično inženjerski aspekt

3. Srećković M. et al., 2004.

4. Polić-Radovanović, Borna, Milosavljević, 2005. 

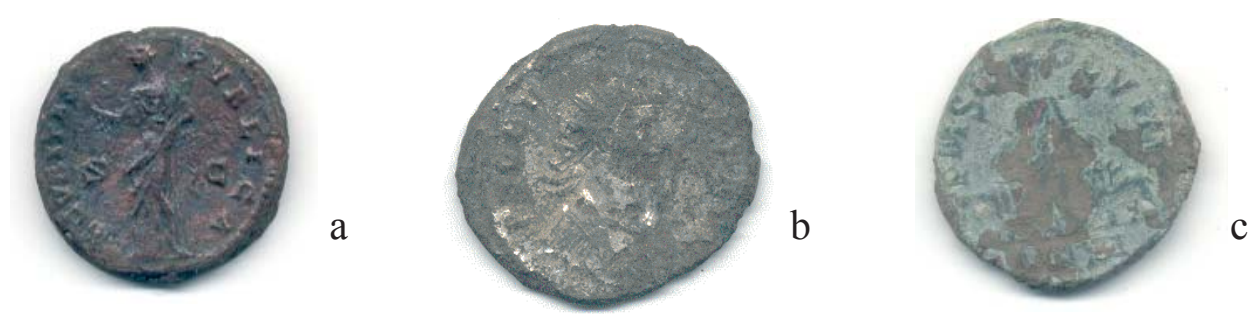

Slika 1. Kovani novac Viminaciuma: a-Antoninus Pins (138- 161) AS, b- Probus (276-282), c-Trajan Decius (249-251)

pomera na polje ambivalencije fizički agregatnog, a smisaono kreativno egzistencijalnog. U tom smislu indikativan je tehnološki proces kovanja karakterističan za izradu novca u rezličitim epohama, koji postavlja univerzalna tehnološka pitanja restauracije predmeta ne samo $u$ drugačijim razdobljima, nego i u istom vremenu. Reč je o nestereotipnom jedinstvu različitog, nestatičkom fenomenu u jedinstvu progresije i umnogostručavanja u smislu beskrajne varijacije jednog osnovnog poremećaja.

Arheološki nalazi kovanog novca, sa lokaliteta Viminacijum $^{5}$ (Sl. 1) pripadaju serijama carskog, kao i lokalnog novca kovanog 239/240 - 254/255. godine, osim u godinama 248/249 i 253/254. Na-

5. Spasić-Đurić D., 2002. lazi novca obuhvataju uzorke različitog kvaliteta očuvanosti materijala i forme. Osim samog materijala, predmet analize odnosi se i na sam tehnološki proces obrade deformisanjem (kovanjem) koji presudno utiče na novo stanje odabranog materijala.

U postupcima oblikovanja deformisanjem, potrebno je da se odredi deformisanje u promenljivom preseku (Tabela 1) kada materijal plastično teče. Prema konvenciji, tečenje materijala se posmatra od tačke kada se presek počinje bitno da razlikuje od početnog poprečnog preseka uzorka koji plastično deformišemo. Oblik deformisanosti uzoraka novčića govori o procesu deformisanja koji ga je produkovao. Važna veličina koja ima uticaj na ponašanje materijala tokom plastične

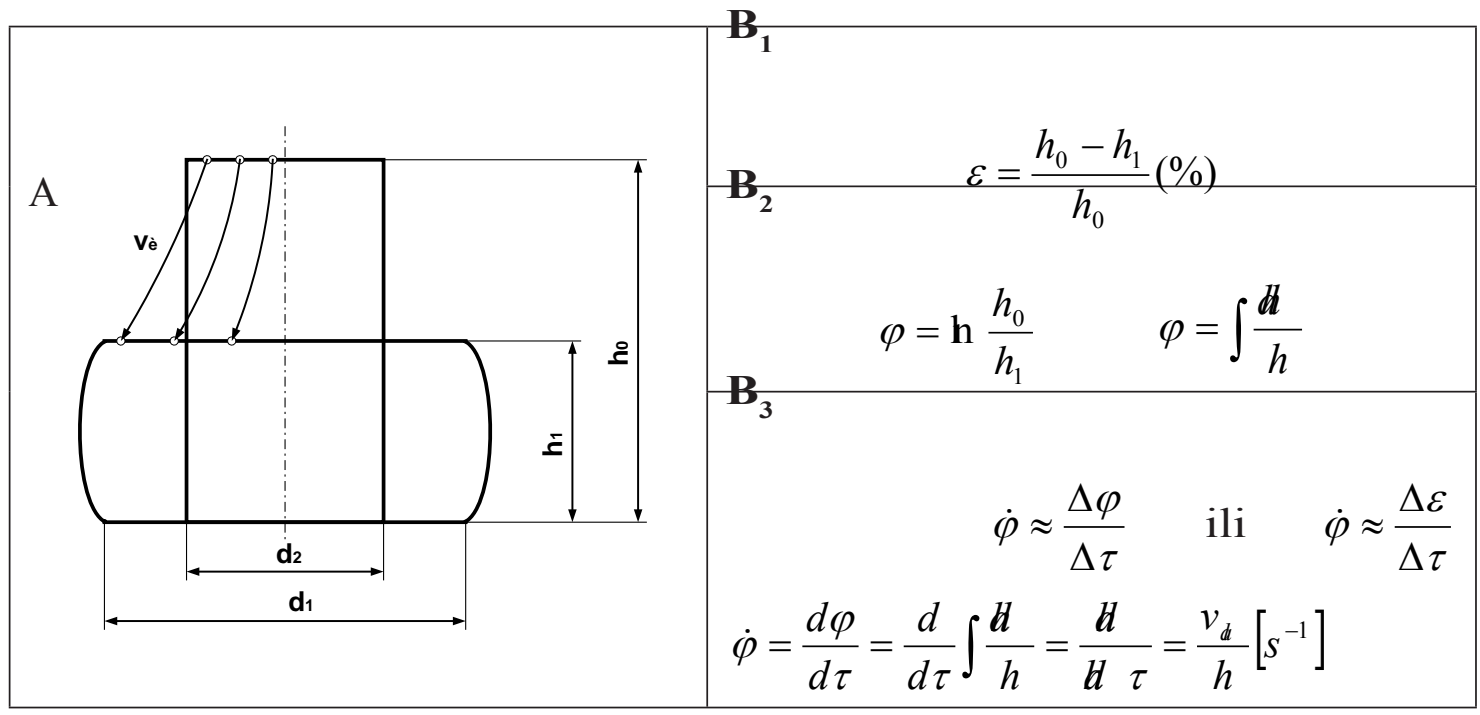

Tabela 1. A- Početni i konačni presek i visina obratka, brzina i put čestica na čelu obratka; B- Stepeni deformacije: 1-relativni stepen deformacije, 2- logaritamski stepen deformacije, 3- brzina deformacije 


\begin{tabular}{|c|c|c|}
\hline materijal & temperatura $\mathrm{C}^{\circ}$ & Korozija metala mm/god \\
\hline bakar & 20 & $\begin{array}{c}0.006-0.0014 \\
<0.1\end{array}$ \\
\hline \multicolumn{2}{|c|}{ Stepeni čišćenja korodiranih slojeva laserskim snopom [ ] } \\
\hline & & \\
\hline & & \\
\hline
\end{tabular}

Tabela 2. Korozija materijala

deformacije je brzina deformacije. Povećanjem brzine i stepena deformacije (naroćito kod hladne deformacije) dolazi do očvršćavanja materijala, a s tim u vezi povećava se naprezanje plastičnog tečenja i otpor deformisanju, a smanjuje se deformabilnost. Pojava povećanja otpora deformisanju sa porastom brzine deformacije izrazita je u slučaju kada se proces odvija iznad temperature rekristalizacije (topla deformacija).

U analizi stanja uzoraka je od izuzetne važnosti podatak o uslovima u kojima su uzorci pronađeni, jer u prirodnim uslovima bakar korodira (Tabela 2) i gradi okside, karbonate, sulfide i druga jedinjenja koja su nasuprot bakru postojana $u$ atmosferskim uslovima. Cilj delovanja laserom na površinu uzorka je otklanjanje svih naslaga (skrame, korozije) koje pokrivaju površinu novčića (Tabela 2) i u tom smislu određujemo talasnu dužinu, vrstu impulsa (najčešće je to Q switch režim). ${ }^{6}$

Važni su parametri i učestanost ponavljanja impulsa, divergencija snopa, oblik impulsa i "rep impulsa", kao i parametari samog lasera, a pre svega trenutna snaga u maksimumu. Prebrisavanje se vrši sa tačno određenim brojem impulsa, po planu koji se precizno primenjuje za svaki specifikum ponaosob, sa različitom repeticijom, u atmosferi odgovarajuće temperature, vlažnosti 6. Yang Sook Koh, 2006. i pritiska. U Tabeli br. 3 date su slike dobijene skenirajućom elektronskom mikroskopijom čišćene površine primenom TEA $\mathrm{CO}_{2}$ lasera, sa optičkom profilometrijom i SEM slike efekata izlaganja površine bakarnog uzorka delovanjem $\mathrm{Nd}^{3+}$ : YAG lasera sa udvojenom frekvencijom, ${ }^{7}$ sa posebnim osvrtom na izgled površine koja ima kovanu podlogu. ${ }^{8}$

Ispitivanje fenomena naprezanja sa aspekta semantike, u sklopu istraživanja narušenog umetničkog (arheološkog) artefakta proširuje dosadašnja razumevanja modela ponašanja tela izloženog deformacijama.

Korišćenje ovih aparata može biti svedeno na direktnu zamenu eksperimentalno određenih pomeraja ili deformacija u odgovarajuće formule, zatim na komparativnu analizu rezultata eksperimenta sa teorijskim proračunima na osnovu nekog usvojenog matematičkog modela ili na kombinovanje proračuna i eksperimentalnih podataka u zajedničkoj metodi. Posebno mesto zauzimaju metode analogije.

Reflektivnost većine metala je visoka u oblasti oko $10 \mu \mathrm{m}$, što znači da je koeficijent sprege jedva par procenata za slučaj $\mathrm{CO}_{2}$ lasera koji zrači u ovoj oblasti. Za talasnu dužinu od $1 \mu \mathrm{m}$ - oblast

7. Luk'yanchuk B.S., 2002.

8. Čekada M., Panjan P, 2004. 


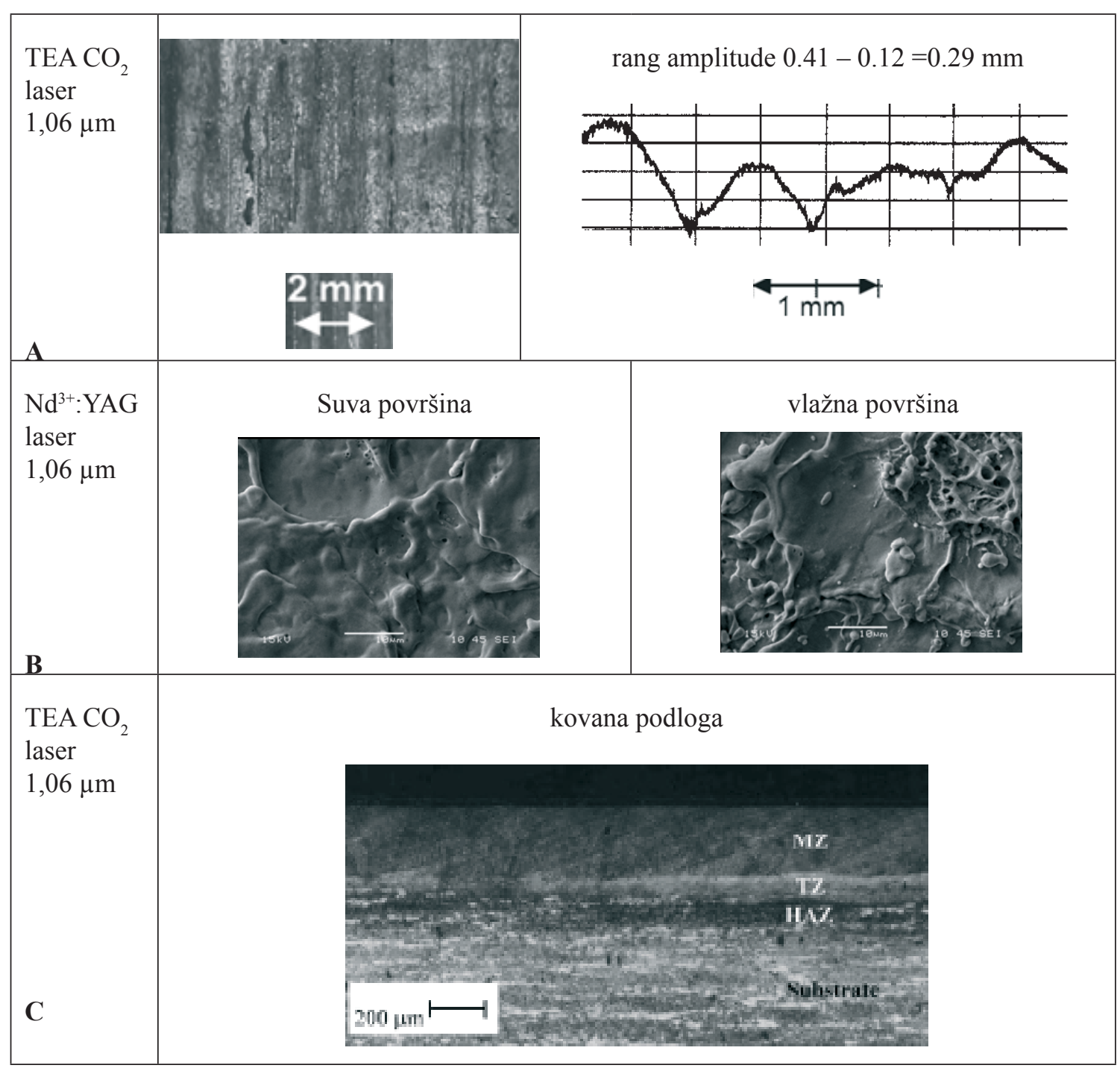

Tabela 3. A-Tipičan SEM prikaz regija čišćenja TEA $\mathrm{CO}_{2}$ laserom i optička profilometrija; SEM fotografije bakarne površine posle dejstva lasera udvojene frekvencije [9]; SEM prikaz laserskog topljenja površine kovane podloge ( $\mathrm{MZ}$ - rastop, TZ - zona uticaja toplote) [10]

rada $\mathrm{Nd}^{3+}$ : YAG lasera, ovaj koeficijent je mnogo povoljniji i to objašnjava zašto se ovim laserom postiže više nego istom snagom $\mathrm{CO}_{2}$ lasera9 (Tabela 4).

Ono što uopšte omogućava da ovi laseri obrađuju materjial je promena reflektivnosti sa povećanjem temperature uzorka. Već i onih par procenata apsorpcije zračenja dovodi do zagrevanja radnog predmeta, što u većini slučajeva smanjuje reflektivnost, tako da ako se saopšti

9. Kearns, A. et al., 1998. dovoljno energije dolazi do opadanja reflektivnosti do malih vrednosti. Istovremeno i drugi procesi utiču na vrednost reflektivnosti, a uklanjanjem materijala stvara se krater tako da snop doživljava više refleksija, čime se takođe povećava koeficijent sprege.

Generalni trend obrade materijala laserskim snopom je upotreba sve kraćih impulsa. To omogućava da zona termalnog uticaja ne bude mnogo veća od zone uticaja laserskog snopa. Kada je laser kontinualan sa prekidanjem (uključenjem 


\begin{tabular}{|c|c|c|}
\hline Stanje površine & Refleksivnost & Apsorpcija \\
\hline Oksidisana površina & $14 \%$ & $86 \%$ \\
\hline Jednom laserom očišćena površina & $39 \%$ & $61 \%$ \\
\hline Dva puta laserom čišćena površina & $44 \%$ & $56 \%$ \\
\hline Mehanički polirana površina & $37 \%$ & $63 \%$ \\
\hline
\end{tabular}

Tabela 4. Oksidisana površina i stanje posle čišćenja $\left(\mathrm{Nd}^{3+}:\right.$ YAG laser $\left.1,06 \mu \mathrm{m}\right)$ na talasnoj dužini $\lambda=527 \mathrm{~nm}[11]$

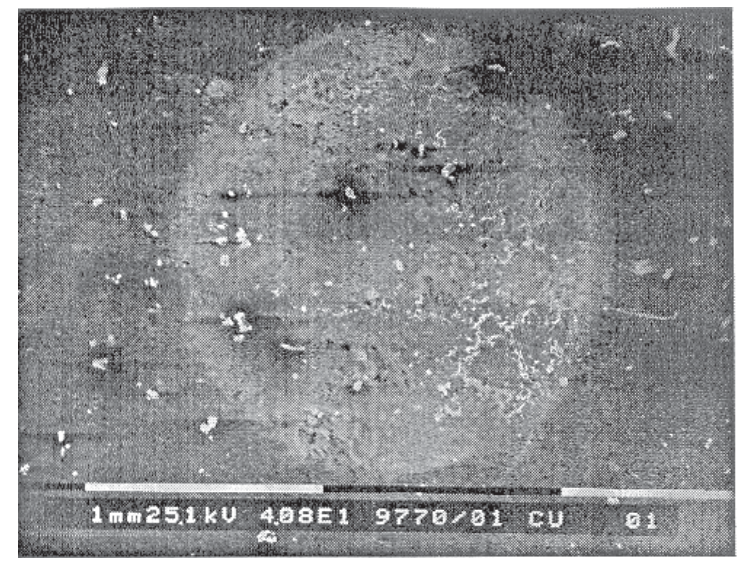

Slika 2. Povreda $\mathrm{Cu}, \mathrm{E}=0,2 \mathrm{~J}$.

a

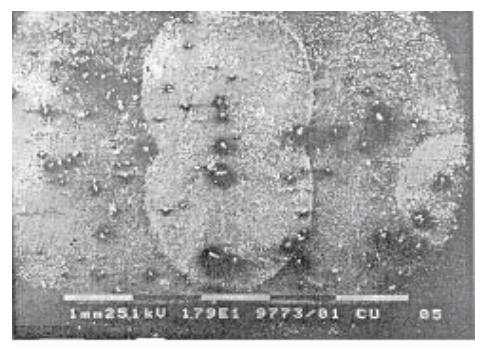

b

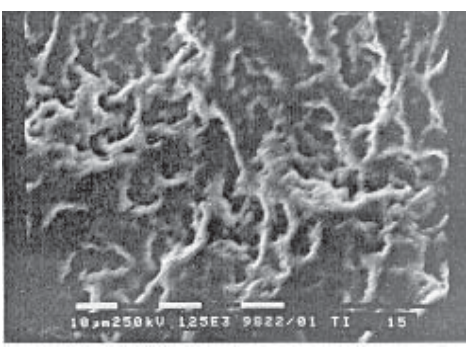

Slika 3. Povreda $\mathrm{Cu} \mathrm{E}=2,6 \mathrm{~J}$ a

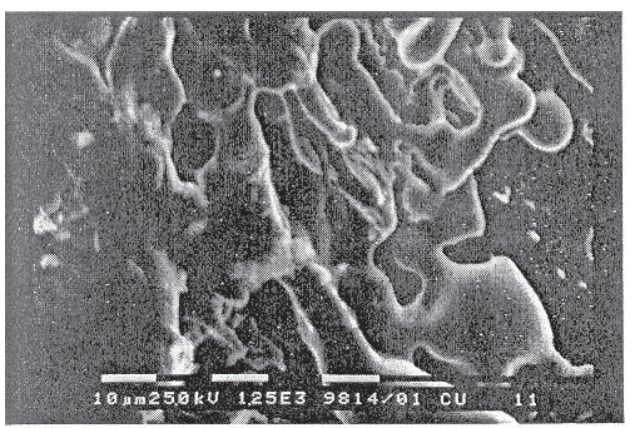

b

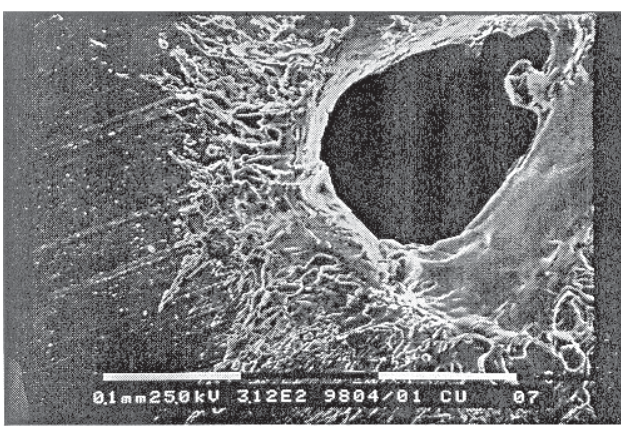

Slika 4. Povreda $\mathrm{Cu} E=0,2 \mathrm{~J}$ i $\mathrm{E}=2,6 \mathrm{~J}$ 
i isključenjem snopa) od velike je važnosti da su vremenski intrevali u kojima snop interaguje sa materijalom tačno određeni. Dužina intervala direktno utiče ne samo na dubinu nego i na oblik povrede. Ukoliko je interval prekratak, dubina bušenja postaje nedovoljna. Ukoliko je vremenski interval predugačak onda dolazi do deformacije zidova povrede, što je takođe nepovoljno u velikom broju slučajeva.

Na slikama 2-4. date su dobijene povrede materijala dubine $\sim 1 \mathrm{~mm}$, delovanjem ruby lasera $\mathrm{u}$ Q switch režimu ( $0,2 \mathrm{~J})$ na atmosferskom pritisku i u vakumu. Na slici br.2. prikazana je povreda u obliku kruga prečnika d 1,79 mm, a na slici br. 3 povreda $\mathrm{Cu}$ sa dijametrom prečnika $\mathrm{d} \sim 2,7 \mathrm{~mm}$ i detaljima iz centralne regije i regije kratera. $\mathrm{Na}$ slici br. 4. prikazane su povrede dobijene u vakumu $(0,66 \mathrm{mPa})$ različitim vrednostima energija (0,2 J i 2,6 J).

Sprega između laserskog zračenja i materijala koji se obrađuje jedan je od promenljivih parametara, ali on se značajno menja u toku procesa, pa ga ne treba isključivo identifikovati sa reflektivnošću.

Kod zračenja koja se koriste pri obradi materijala, neposredno posle topljenja površine formira se plazmeni oblak, koji se velikom brzinom kreće u smeru izvora zračenja i zaklanja materijal. U tom smislu može se zaključiti da bi delovanjem lasera na novčiće koji za osnovu imaju bakar, bilo moguće izvršiti čišćenje površine primenom $\mathrm{Nd}^{3+}$ : YAG lasera. Očekivana bi bila pojava plazme zelene boje.

\section{RESUME \\ Laser's Identification of Archaeological Materials Using Comparative Analysis of Equivalent Bases}

Within conservation and restauration, a science of materials has a fundamental character for the object or collection which are the subjects of protection. New technologies, contemporary laser's methods in the first place, enable a state diagnostic and give the answers about an optimal preventive protection and control of exhibit.

This paper presents the results of laser application on materials with the equivalent bases to the materials of coinage from Viminaciuum, the captal of Rome's conty Gornja Mezija.

\section{LITERATURA:}

\section{Milosavljević i dr. 2002}

Milosavljević A., Polić-Radovanović S., Radovanović R., Sadejstvo tehnologije $i$ kulture $u$ očuvanju nacionalne baštine, Zbornik radova

“'Tehnologija, kultura, razvoj”, str. 262-269, Udruženje

"'Tehnologija i društvo", Beograd, 2002

\section{Vejming 2006}

Vejming Li, Pregled istorije kineske bronze, Kraljevska bronza dinastija Sja, Šang i Džou, Muzej istorije Jugosavije, 2006

\section{Pimi 2000}

Pini R., et al., Tests of laser cleaning on archaeological metal artefacts, J. Cult. Heritage 1, 2000

\section{Milosavljević 1996}

Milosavljević A. et al., Laser beam effects on $\mathrm{Cu}$ and $\mathrm{Ti}$ in vacuum and the air, Vacuum, Elsev ier Science Ltd, Great Britain, 1996 


\section{Srećković 2004}

Srećković M. et al., Laser application in processing, technology, conservation and expirience of artwork based on light metals, Journal of Metalurgy, Vol. 10 (3), 2004

\section{Polić-Radovanović 2005}

Polić-Radovanović S., Borna N., Milosavljević A., Neki ekološki aspekti primene lasera (delovanje ekoloških faktora na kulturnu baštinu-dejstvo aerosola), Zbornik radova 49. Konferencije za ETRAN, tom III, Budva, 5-10. jun 2005

\section{Spasić-Đurić 2002}

Spasić-Đurić D., Viminacijum, glavni grad rimske provincije Gornje Mezije, Narodni muzej Požarevac, Požarevac, 2002

\section{Yang Sook Koh 2006}

[8] Yang Sook Koh, Laser Cleaning as a Conservation Technique for Corroded Metal Artifacts, Luleå University of Technology Department of Applied Physics and Mechanical Engineering Division of Manufacturing Systems Engineering, Doctoral thesis, 2006

\section{Luk'yanchuk 2002}

Luk'yanchuk B.S., Laser Cleaning, World Scientific Publishing, Singapore, 2002

\section{Čekada, Panjan 2004}

Čekada M., Panjan P, Laserski postopki zaščite površin, Vakuumist, 24/4, 2004

\section{Kearns 1998}

Kearns, A. et al., Laser removal of oxides from a copper substrate using Qswitched Nd:YAG radiation at $1064 \mathrm{~nm}, 532 \mathrm{~nm}$ and 266nm, Applied Surface Science Vol 127-129, 1998 